\title{
SPEECH PERCEPTION DEFICITS AND THE UNDERLYING NATURE OF DEVELOPMENTAL DYSPHASIA
}

\author{
MÁRIA GÓSY
}

\begin{abstract}
Developmental dysphasia is a specific and primary disorder of oral language development which occurs in children with normal hearing and normal intelligence, having neither objective neurological diseases nor emotional or communicative disorders, and is characterised by more serious deficiencies in perception than in production processes. The relevant literature has mainly been focusing on expressive linguistic skills so far; whereas with respect to the mechanism of speech perception, only certain component processes have been investigated. The present paper presents pioneering work in exploring specific perception disorders in dysphasic children and discusses interrelationships of the operation of component processes within the total system of speech perception. On the basis of the foregoing, delayed speech and the dissociation of production and perception are discussed in the framework of current theories of language acquisition and hypotheses concerning the operation of defective processes.
\end{abstract}

\section{Introduction}

Children's development of speech perception begins in the very first weeks of life. Newborn babies are able to make fine distinctions among speech sounds after just a few weeks. The perceptual loss suffered by the end of the first year is a consequence of the fact that the little child continues his interaction with his native language (Berko Gleason-Bernstein Ratner 1998). During first language acquisition, the child's mother-tongue perception base and operative strategies of perceptual processes gradually take shape from age one onwards. Children start speaking at the same age all over the world as if this happened at the signal of an internal "biological clock" (Aichison 1976). A well-known phenomenon of infantile language acquisition disorders, however, is delayed speech. The apparently normally developing child fails to start speaking at the expected time, or communicates with just a few words, often expressing what he means by gestures and making himself understood in that way. It seems as if that biological clock failed to strike even though the child's hearing and intelligence are not defective. We speak of delayed beginning of first language acquisition if, at the age of 2;0 for a girl and 2;6 
for a boy, a child fails to speak or just uses a few words (is in the period of holophrases). A child who does not begin to speak by the age of two (and a half) - irrespective of the actual language being acquired - is taken to be a delayed speaker (Ludlow 1980a; Paul-Shiffer 1991). Such delay may have a number of negative consequences for all processes of speech, or specifically for some processes, and even may have adverse effects on learning to read and write later on.

The phenomenon is referred to by various terms, depending on which aspect is emphasised, whether it is the fact of delay ('speech/language delayed children', cf. Richardson 1983; Psarommatis et al. 2001, or 'late-talking children', cf. Paul-Shiffer 1991), the assumed cause ('central auditory processing disorder', cf. Neijenhuis et al. 1999), the difference from aphasia ('developmental dysphasia', cf. Wieke 1977; Duvelleroy-Hommet et al. 1995), or whether the existing language state is generalised ('language impairment/disability' or 'specific language impairment', cf. Ludlow 1980b; Crystal et al. 1989; Palmour 1997 ) or the consequences are highlighted ('learning disorders/disabilities', cf. Kraus et al. 1999). Hence, it is not only the case that a multitude of terms are being used but what often results in misunderstandings is that the same expression is used to refer to diverse types of disorders whereas the same phenomenon is referred to by diverse names. For instance, the term 'dysphasia' might be defined as the 'disturbance or the loss of ability to comprehend, elaborate or express language concepts' (Cromer 1991). In this definition, controversial as it is, the confusion with 'aphasia' is evident. Specific language impairment can obtain without delayed speech. 'Developmental dysphasia' also occurs as synonymous with 'specific language impairment' or 'languagelearning disability'. The problem is partly due to the fact that the diagnostic criteria and etiology of developmental dysphasia are still inadequately defined (Palmour 1997).

In this paper, the impairment of children with delayed speech development will be called 'developmental dysphasia'. Thus, the problem at hand can be clearly distinguished from children's aphasia, while it specifically includes the delayed beginning of speech. Furthermore, it includes the fact of language disturbance (without any reference to the consequences or the state itself). In our view, developmental dysphasia is a specific and primary disorder of oral language development which occurs in children with normal hearing and normal intelligence, having neither objective neurological diseases nor emotional or communicative disorders, and is characterised by more serious deficiencies in perception than in production processes (whatever problems the child's expressive language shows). This approach is partly in harmony with some 
definitions found in the literature (e.g., Duvelleroy-Hommet et al. 1995; Kovac et al. 2001), but puts more emphasis on the dissociation of production and perception. It has also been shown that nonverbal acoustic processing works well with these children, too, therefore speech perception difficulties do not result from a possibly poor hearing performance (Ludlow et al. 1983; Rosen et al. 1997).

The diversity of terminology may reflect problems of definitions, or rather of the ideas behind them. All this is compounded by the fact that, whenever the biological clock fails to strike and the child does not begin to speak at the expected age, the process of first language acquisition may go on in diverse ways, showing wide individual variety (obviously not independently of the reason for the delay). The problem may cover the whole linguistic organisation but it may also be restricted to the articulatory or perceptual mechanisms, to the working of the mental lexicon, or any combination of these.

These problems of definition and content also suggest the controversial nature of the theories underlying them. There is no extant theory that would unambiguously account for the normal, as well as the non-normal, processes of first language acquisition. The acquisition of the mother tongue is a phenomenon that many theories set out to explain. Along with the major trends, several hypotheses are known that are amalgamations of certain aspects of two or more theories (a fairly recent example is emergentism, cf. MacWhinney 1998). The five most comprehensive hypotheses are as follows. (i) Genetically encoded language faculty. It assumes that the ability to perceive and acquire certain linguistic relationships is innate to the child. There may exist certain pre-set specifically linguistic strategies for the acquisition of language structures (Chomsky 1957). (ii) Learning theory is based on the assumption that language development is a result of adults' reinforcement and general principles of the learning process. It includes at least three kinds of learning: classic conditioning, operant conditioning, and social learning. (iii) Cognitive theory. According to this hypothesis, language is a subordinate part of cognitive development, dependent on the attainment of various concepts. (iv) The social interactionist theory claims that children acquire language in part through the mediation and help of others, rather than purely through their own mental activity in processing adult language. (v) Connectionist models are based on processing units that are responsible for connections, associations during language learning.

The question, then, is which theory can best account for delays in language acquisition and the resultant dissociation between speech perception and production. Many different hypotheses are known (cf. Bishop 1992), 
most of which can be subsumed under either the group of competence-based or that of performance-based theories. In the first case, the problem is explained by incomplete knowledge, missing rules/principles, or incomplete linguistic constraints. On the other hand, performance-based theories assume that the child's linguistic impairment is a secondary phenomenon, essentially a consequence of non-linguistic processing impairments, that is, it is a kind of functional linguistic processing deficit (Gathercole-Baddeley 1990; Evans 2001). There is also a view according to which the explanation for language acquisition problems can be found in psychological theories of learning (Obler -Gjerlow 1999). Several hypotheses have also been advanced to explain the dissociation of perception and production. One of these claims that the basic linguistic deficiency of the dysphasic child is manifested in the faulty operation of his perceptual processes (cf. Coleman 1998). The issue of the independence of the language faculty is raised in several theories (cognitive theory, connectionist models). With an autonomous language faculty, the problems of both impairments and dissociations can be explained as a highly specific deficit in a language "module". In view of the foregoing and our own results, the following statements can be made.

(i) Deficiencies of first language acquisition should receive an attempted explanation within models of normal language acquisition.

(ii) Performance-based theories offer a better solution since they account for functional and operational impairments, dissociations, as well as the working of correction mechanisms (cf. the claim that linguistic functions and cognitive operations are not the same: Cromer 1991).

(iii) The performance-based approach involves claims taken from several theories of language acquisition (the fact of genetic encoding, the relative independence of linguistic operations, the role of the adult model). Hence, further details have to be clarified before the performance-based approach can be more strictly associated with one or two theories of language acquisition.

In terms of the performance-based theory, a child who begins to speak too late is taken to be dysphasic as long as, due to the delay, he shows some disturbance in any area of language use. For a long time, delayed speech development was taken to be a problem of speech production. By now it has become evident for both theoretical and practical purposes that it is the state of the total linguistic system that has to be investigated in such cases, including speech perception processes. Therefore, developmental dysphasia is seen as an overall delay in language development indicating that some deficit 
is affecting all areas of language acquisition. The crucial observation with dysphasic children is that, after the age of three, their speech production starts developing and their ongoing language acquisition concerns all areas of language except the processes of speech perception. This may be related to the reaction of the adults surrounding the child (instinctive reinforcement primarily concerns the expressive side), a fact that lends even more support to the social interactionist theory, and thus indirectly to the performance-based hypothesis.

Delayed speech may have a number of causes, both organic and functional (the most frequent causes are mental retardation, deafness, hearing impairment, autism, dysarthria, stammering, stimulus-deprived environment, psychic disturbances, specific language disorder). Causes that have to do with neurological disorders may be functional or organic; whereas operational and environmental causes are functional ones. In the latter cases, psychic and genetic origins can both be assumed. The factors leading to dysphasia being so numerous results in a syndrome-like character of the whole problem. The dysphasic child, lacking appropriate speech production, will use gestures or hand-signs in order to express his thoughts. These environmental or body signs, gestures, are previously visually perceived, identified, and adapted to the child's personal needs. In the interaction between child and adult, a special kind of "bilingualism" emerges: the adult produces verbal messages for the child, whereas the child responds to the verbally decoded messages by gestures or signs, and uses the latter for communicating his own ideas and delivering his messages (Gósy 1998). His communication is thus non-verbal. The adult is forced to process non-verbal messages but then reacts to them verbally again. Permanent code-switching takes place: in the case of the adult, non-verbal processing is followed by verbal reaction, whereas with the child, verbal processing is followed by non-verbal response. Gestures in this case represent some kind of language. This raises the theoretical question of whether there may exist language in one's mind without being manifested in speech in the usual manner. Steinberg (1993) offers a simple criterion for deciding the issue of language vs. non-language. He says a person who cannot speak possesses language if he is able to communicate by signs in the same way as others communicate by speech. This can be taken to cover the sign system of dysphasic children as well as the various sign languages used by the deaf and the severely hard of hearing. The signs used by dysphasics - though undoubtedly manifestations of 'language' - enable them to communicate messages that are by far more restricted than the ones that can be conveyed by speech. It is astonishing, at the same time, how complex trains of thought 
these children often try to communicate. Eric Lenneberg reported on an eight-year-old boy who had learned to understand speech despite his congenital inability to speak (cf. Jakobson 1971, 293). Jakobson interprets this as evidence for a higher degree of autonomy of the decoding process; he also refers to the fact that children who have not yet started speaking also understand adults. This latter argument is misguided since the speech processing of pre-speech children is fundamentally different from the process of speech perception/comprehension a couple of years later. It is nevertheless a fact that several cases are known in which what operates is almost exclusively the perceptual side of language activity. The present author also had the privilege of examining a seven-year-old child who had been born with a special and rare disease: part of his left hemisphere, including his Broca's and Wernicke's areas, were missing. The little boy was incapable of articulate speech; yet his level of sentence comprehension, measured in terms of a picture selection test, corresponded to that of a five-year-old child of normal development. He was furthermore able to discriminate sounds to a limited degree; his performance in the relevant test reached the level of four-year-olds.

Developmental dysphasia thus means a delay both in speech production and in speech perception and speech comprehension; but a lot more results of experiments and examinations are available with respect to such children's speech production than concerning their mechanisms of speech processing. Our knowledge of their speech perception is very limited; investigations thus far have mainly centred on phonological processing. The present paper tries to characterise the speech perception processes of children who started speaking around age three, that is, children whose first language acquisition began with a delay, but whose hearing and intelligence are both normal. We have chosen nursery pupils and schoolchildren whose linguistic functions exhibit no other difference from the normal case and whose articulation problems (if any) concern at most one or two speech sounds. Our aim was to demonstrate that a child with delayed speech, even though his speech production has subsequently improved to normal level, keeps on falling short of age-bound expectations with respect to his perception processes for quite a number of years. In other words, developmental dysphasia as a certain degree of impairment of first language acquisition continues to exist. Our hypothesis is that the dissociation between mother-tongue production and perception, rather than disappearing, becomes even more pronounced after the child's speech production has become normal. It appears that the child comes to meet age requirements in his speech production "at the expense of" his processes of speech perception. We assumed that developmental dysphasia initially just 
means a simple delay and that it is in cases where it continues to exist for a long time that it turns into an actual impairment. This hypothesis is connected with the relative independence of speech perception from speech production in a way that, in cases of impairment, these two processes develop a lot more differently than in normal language acquisition. Our psycholinguistic approach pays attention to both production and perception since for a child with speech problems both may be the primary source of the deficit. Figure 1 (overleaf) illustrates the scheme of interdependence of production and perception (based on Stackhouse-Wells 1997). If our hypothesis turns out to be confirmed, then this has great practical significance, too. If the process followed by these children is the same as it is with normally developing children but delayed, then training based on the normal language acquisition process is appropriate. If it is not, but in fact is deviant, then the training procedures should be patterned according to specific needs (Ludlow 1980b).

\section{Method, material, and subjects}

In our experiments, we have used five perception tests (GMP2, GMP4, GMP5, GMP10, GMP18) of the GMP standardised diagnostics package for the examination of speech perception and comprehension (Gósy 1999a). The first four of these specifically and quasi-separately examine the acoustic, phonetic, and phonological levels of the speech perception process (using test sentences) and serial perception (using nonsense sound sequences), respectively, whereas the fifth probes transformational perception performance. Although the child has to repeat sentences in some of these tests, this task does not require him to understand the sentences or reconstruct their grammatical forms. The materials of the individual tests were compiled in harmony with the classical procedures of speech perception tests (Neijenhuis et al. 1999). GMP2 is an examination of the acoustic level of speech perception. The language material consists of ten sentences tape recorded as spoken by a male announcer, then masked by white noise (the signal-to-noise ratio is $4 \mathrm{~dB}$ on average). The age-required level of correct recognition of the sentences witnesses the normal working of this component process. The task of the child is the immediate repetition of the noise-masked sentence. Examples: A repülógép most szállt le 'The aeroplane has just landed', Az ózikét kergeti az oroszlán 'The roe is being chased by the lion'. The expected values are $80 \%$ for a five-year-old, and $90 \%$ for a six-year-old child. From age seven onwards, all ten sentences are expected to be repeated correctly. GMP4 is an examination of the phonetic 


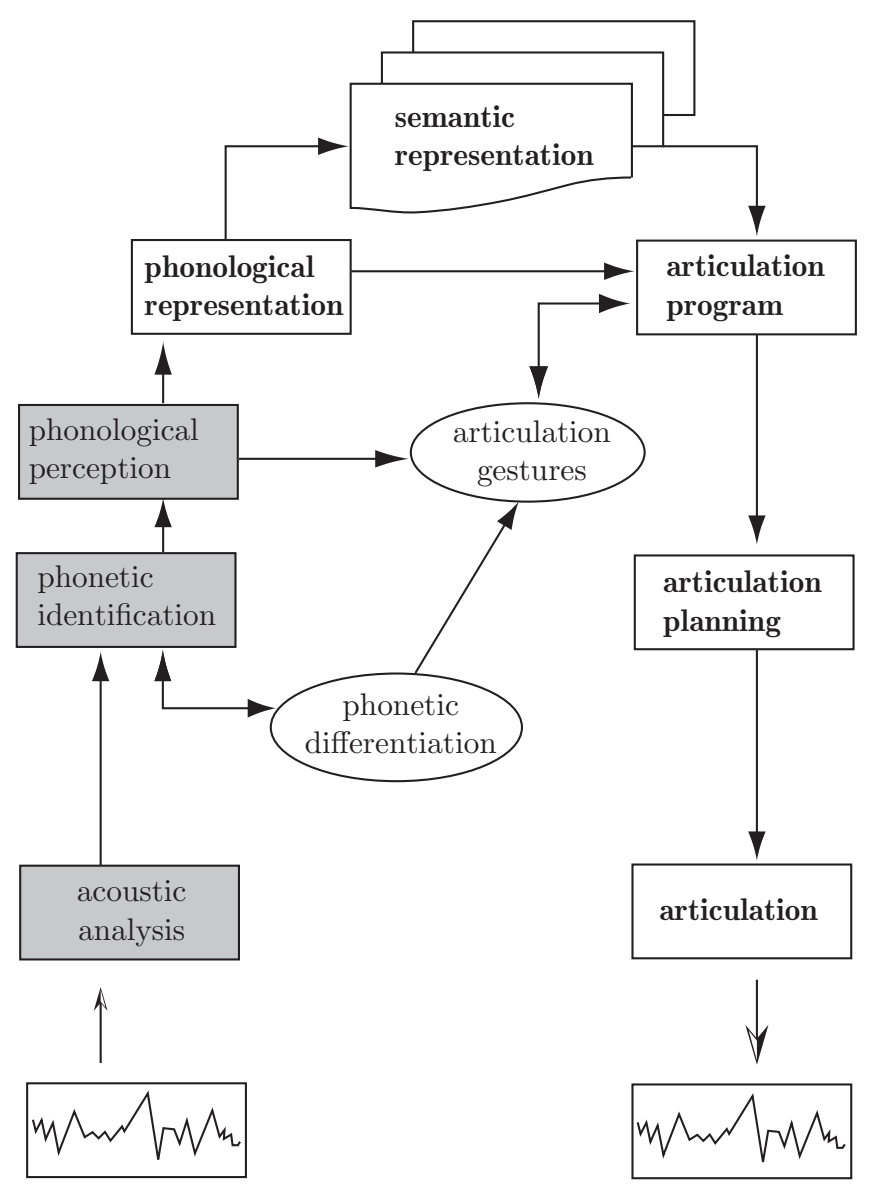

Fig. 1

The assumed interaction of speech production and speech perception (based on Stackhouse-Wells 1997)

level of speech perception. The language material of this test also consists of ten sentences tape recorded as spoken by the same male announcer (e.g., A vonat nyolc órakor indul 'The train starts at eight o'clock', Kapcsold be a televiziót! 'Turn on the TV!'). The ten sentences were filtered using a CSL 4300B digital signal processing system such that the useful frequency range was roughly $1000 \mathrm{~Hz}$ wide (pass-band filtration between $2200 \mathrm{~Hz}$ and $2700 \mathrm{~Hz}$, the filter slope was 18 octave/s). By having the sentences repeated, it is possible to evaluate the identification by the child of the specific acoustic cues 
of the speech sounds as well as their integration into phonetic processing (cf. Ball 1995). The expected value is $100 \%$ already from the age of five. There are various tasks to evaluate the child's phonological awareness (cf. Stackhouse-Wells 1997). In the present experiment, two tests serve this, GMP5 tests phonological processing in the strict sense, whereas GMP10 tests seriality. The language material of GMP5 consists of ten sentences tape recorded as spoken by a male announcer, then artificially speeded up by $25 \%$. The average tempo of the ten sentences thus became 14 sounds/s, somewhat faster than the average Standard Hungarian speech tempo (for comparison: the attested limiting values of the articulation tempo of 9-12-year-old native Hungarian children are 8.9 to 13.7 sounds/s, cf. Menyhárt 2002). The meaning and/or grammatical structure of half of the sentences are such that they generally surpass the linguistic knowledge of 5-9-year-old children (e.g., Öt is beidézték a tárgyalásra? 'Has he also been subpoenaed for the court hearing?', Attkokat szórt mások fejére 'He hailed down curses on other people's heads'). The purpose of this deliberate limitation of the levels of meaning and associations is to make the child take advantage of his lower levels of speech perception to a larger extent. The expected values are $80 \%$ for a five-year-old, $90 \%$ for a six-year-old, and $100 \%$ for a seven-year-old (or older) child. GMP10 examines serial perception. Ten nonsense sound sequences (menelékej, siszidami, $z s e r e ́ b$, etc.) are to be repeated by the child in order for us to examine the interrelation of his speech perception and speech production systems. The test situation is similar to the real-life situation in which the child hears a new word and tries to say it for the first time. Already at the age of five, the child is expected to perform almost perfectly (90\%); from age six onwards, the standard value is $100 \%$. Finally, GMP18 checks up on transformational perception. The test uses twelve coloured cubes. The child is presented with all the cubes, then one of them is identified with the consonant [p]. When the child has understood the relation between the cube and the consonant, there are further tasks to check if his transformational perception reaches the expected level. The test consists of four parts with increasingly complex tasks in which seriality, speech sound identification, differentiation, and direction recognition are all crucially involved (the trigger sequences in the four parts are $[\mathrm{p}, \mathrm{p}] ;[\mathrm{p}, \mathrm{o}] ;$; $[\mathrm{o:}, \mathrm{p}]$; and $\left[\mathrm{b}, \mathrm{o:}, \mathrm{p}, \varnothing_{\mathrm{r}}\right]$, respectively).

The tests were performed individually, lasting an average of 18 minutes per child.

The number of subjects was a total of $\mathbf{1 5 0}$ children, in five age groups (5, $6,7,9$, and 10-year-olds), 30 subjects per group. The five- and six-year-olds were nursery pupils, the seven-year-olds attended the first form of various 
primary schools. The nine- and ten-year-olds were third- and fourth-formers, respectively. In the families of the children examined, similar problems of linguistic development did not occur. All subjects were of normal hearing and intelligence (the former point was checked using the GOH hearing screening procedure based on synthesized speech, cf. Gósy 1992; 1999b). First language acquisition started at around age three with all of them; before that, they used just a couple of words and hand-signs. Most of the children were boys, but the genders were represented diversely in the various age groups (the number of boys was 25 in the five-year-old group, 21 in the six-year-old group, 20 in the seven-year-old group, 16 in the nine-year-old group, and 20 in the ten-year-old group). We did not try to reach a balanced representation of boys vs. girls; in this way, the figures also indicate the observed distribution of the impairment across genders in the given age groups.

Some of the children examined still had a speech defect at the time of the experiment. This concerned exclusively the accuracy of articulation (they did not have any other speech defect); it was observable to a higher degree with the five- and six-year-olds (in almost $80 \%$ and $60 \%$, respectively), whereas a mere $27 \%$ of seven-year-olds, $22 \%$ of nine-year-olds, and $9 \%$ of ten-year-olds had this problem. The pronunciation of vowels was correct with all the children; of the consonants, sibilants and $[\mathrm{r}]$ proved to be difficult to articulate correctly. This corresponds to the physiological articulation difficulties observed with Hungarian children in general; however, in normal development, such articulation problems usually cease to exist around age three. More than two thirds of the participants $(83.3 \%$ of five-year-olds, $73.3 \%$ of six-year-olds, $56.6 \%$ of seven-year-olds, $80 \%$ of nine-year-olds, and $76 \%$ of ten-year-olds) underwent speech therapy between 3 and 7 (for an average of three years).

The statistical evaluation of the data was based on the ANOVA procedure and correlation tests carried out in SPSS for Windows 8.0 software package. In all cases confidence level was set at the conventional $95 \%$.

\section{Results}

We have found significant lag behind the age-required level of performance in terms of all perceptual processes. Considering only average values, we can say that five-year-olds merely showed some delay but their performance curve followed that of normal children (Figure 2). From age six onwards, however, what we had is not simply delay but actual impairment (Figure 3), given 
that the performance curve of our children showed characteristic deviations from the expected normal performance. Acoustic and phonetic perception exhibited lesser lag, but the level of serial and phonological processes was strikingly poor. Compared to those of five-year-olds, the results of the older children "deteriorated"; in other words, the results suggest that five-year-olds performed better than six-year-olds did. In fact, there was some improvement between the two age groups, but in comparison to the level required for their age, the performance of the six-year-olds got worse, i.e., the difference between normally developed and dysphasic children increased.

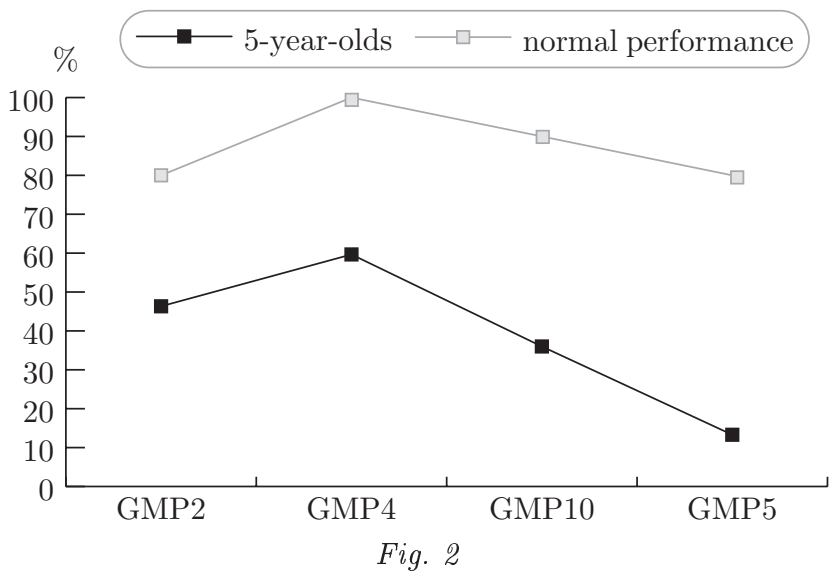

Delayed perception performance of five-year-old dysphasics compared to the expected values

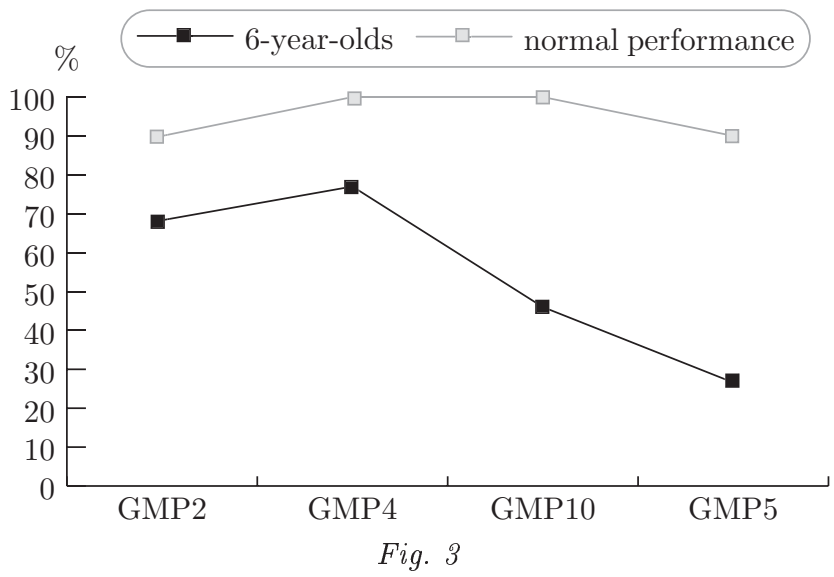

Delayed perception performance of six-year-old dysphasics compared to the expected values 
The performance of the schoolchildren also showed significant lag behind that of normally developing children but the performance of the individual age groups exhibited some improvement in all processes (Figure 4). The values for six- and seven-year-olds showed almost no difference, which means that the speech perception levels of nursery school leavers and first-formers were nearly identical, a level that was far behind expectations. Considering the fact that the perceptual processes are responsible for the acquisition of the written language, we must conclude that our first-formers were not in a position to learn how to read and write without problems. Since even nine- and tenyear-olds failed to reach the required levels of a seven-year-old child (!), it is no wonder that various difficulties or deficiencies had been invariably found with all of them in learning the written version of their mother tongue. The descriptive statistical data obtained for the perceptual processes tested are shown in Tables 1-4 with respect to the five age groups.

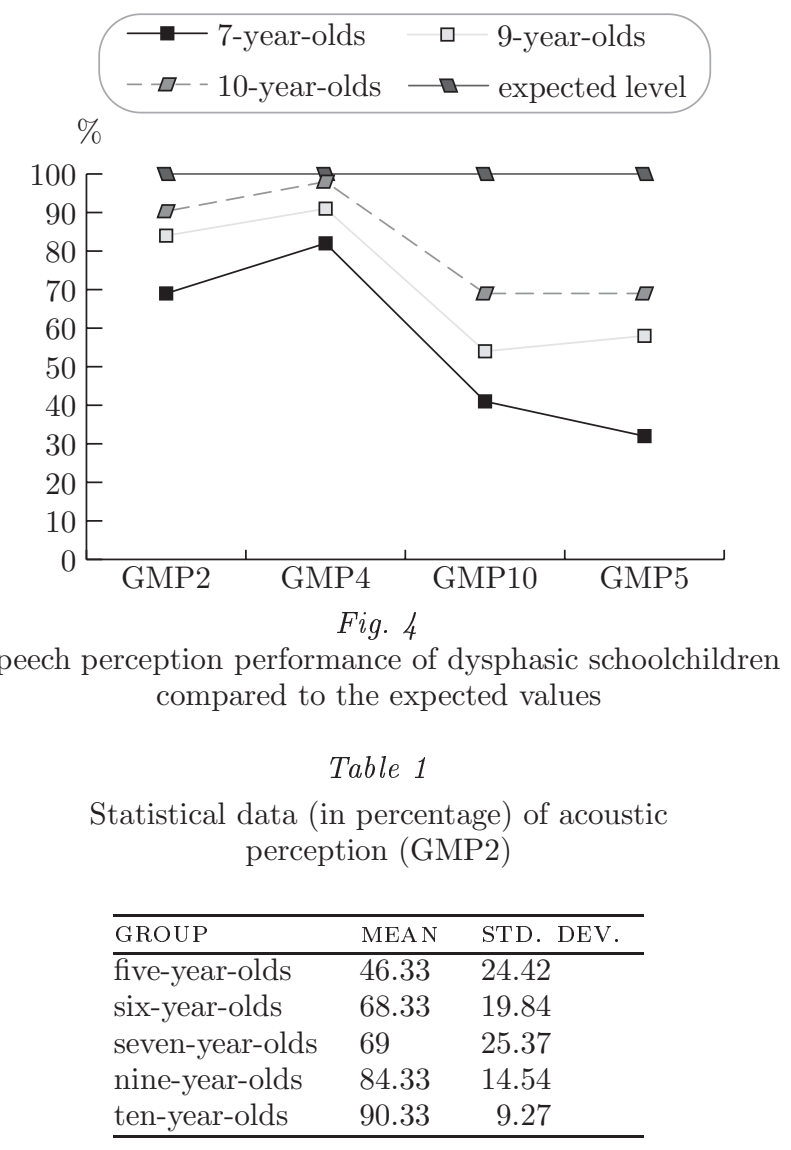

Acta Linguistica Hungarica 49, 2002 
Table 2

Statistical data (in percentage) of phonetic perception (GMP4)

\begin{tabular}{lll}
\hline GROUP & MEAN & STD. DEV. \\
\hline five-year-olds & 59.66 & 30.79 \\
six-year-olds & 77 & 30.30 \\
seven-year-olds & 82 & 26.18 \\
nine-year-olds & 91.33 & 13.82 \\
ten-year-olds & 98.33 & 3.79 \\
\hline
\end{tabular}

Table 3

Statistical data (in percentage) of phonological perception (GMP5)

\begin{tabular}{lll}
\hline GROUP & MEAN & STD. DEV. \\
\hline five-year-olds & 13.33 & 17.08 \\
six-year-olds & 26.66 & 20.73 \\
seven-year-olds & 32.33 & 20.45 \\
nine-year-olds & 58 & 19.72 \\
ten-year-olds & 69 & 23.09 \\
\hline
\end{tabular}

Table 4

Statistical data (in percentage) of serial perception (GMP10)

\begin{tabular}{lll}
\hline GROUP & AVERAGE & STD. DEV. \\
\hline five-year-olds & 36 & 24.43 \\
six-year-olds & 46 & 18.49 \\
seven-year-olds & 41.33 & 22.39 \\
nine-year-olds & 54.33 & 20.95 \\
ten-year-olds & 69 & 22.02 \\
\hline
\end{tabular}

As witnessed by the tables, individual variation with respect to all processes was great in each age group. It was not infrequently the case that $60 \%$ or even $70 \%$ differences were found within the same age group, in the same test. This suggests that developmental dysphasia leads on to disturbed functioning of the perception mechanism to widely different extents.

We have analysed potential interrelationships among individual processes of perception. The statistical data revealed a very strong correlation between GMP2, GMP4, and GMP5 $(\mathrm{r}=0.816)$; that is, whoever performed 
well in acoustic perception, would be highly probable to perform at a similar level in phonetic and phonological perception as well. Correlation with serial perception turned out to be significant, too, even if it was less strong ( $\mathrm{r}=$ 0.435). With developmental dysphasic children whose mother tongue was English, strong correlations had been found between timing problems and speech sound discrimination (Tallal-Piercy 1975). Age determined performance to the smallest extent in serial perception $(\mathrm{r}=0.193)$; in the other processes, it was a stronger determining factor (correlation can be taken to be medium strong: $r=0.351$ for GMP2, $r=0.229$ for GMP4, and $r=0.511$ for GMP5).

We have also analysed differences among the individual age groups on the basis of their performance in the processes tested. We obtained a significant difference in GMP2 between five-year-olds and the rest of the age groups ( $\mathrm{p}=$ $0.000)$, between six-year-olds and schoolchildren $(\mathrm{p}=0.014$ and $\mathrm{p}=0.000)$, and between seven-year-olds vs. nine- and ten-year-olds $(\mathrm{p}=0.021$, resp. $\mathrm{p}=$ $0.000)$. There was no significant difference between six- and seven-year-olds or between nine- and ten-year-olds. In GMP4, significant differences were found between five-year-olds and the older groups $(\mathrm{p}=0.035, \mathrm{p}=0.002$, and $\mathrm{p}=$ 0.000 , respectively), between six- and ten-year-olds $(\mathrm{p}=0.000)$, as well as between seven-year-olds and nine- and ten-year-olds $(\mathrm{p}=0.021, \mathrm{p}=0.000$, respectively). However, there was no significant difference between six-yearolds and seven- or nine-year-olds. Hence, it can be stated that a larger leap of development can be found between the five- and six-year-old age group, as well as, among schoolchildren, between third- and fourth-formers. The statistical results of GMP5 were similar, except that the significant differences occurred at different ages. There was no significant difference between the two nursery groups, between nursery pupils and first-formers $(\mathrm{p}=0.081$ and $\mathrm{p}=0.817)$, or between the two oldest groups $(p=0.221)$. Significant differences were found, on the other hand, between nursery pupils and third/fourth-formers $(\mathrm{p}=0.000)$, as well as between first- and third/fourth-formers $(\mathrm{p}=0.000)$. For GMP10, the differences were usually not significant. Exceptions were those between five-year-olds vs. nine- and ten-year-olds $(\mathrm{p}=0.01$ and $\mathrm{p}=$ 0.000 , respectively) and between six- and seven-year-olds vs. ten-year-olds $(\mathrm{p}=0.000)$.

The development of individual processes usually differs across dysphasihildren; the data revealed the following points. The results we obtained for the acoustic, phonetic, and phonological levels of speech perception exhibited more similarity with respect to development than those for serial perception. The most gradual development was observable in acoustic perception; for phonetic perception, we found a period of stagnation from seven to ten years 
of age; whereas phonological perception developed the most spectacularly at seven and nine years. The performance in serial perception did not change until the age of seven, considerable development started only then. We have to add that - in terms of average values - even ten-year-olds failed to reach age-required performance in three out of the four processes examined. We found especially serious lag in phonological and serial perception. Thus, the perceptual processes that are relevant for the unproblematic acquisition of written language (cf. Tallal 1980), did not or did hardly develop until these children started school, a fact that explains the mostly serious difficulties dysphasic children have to face in learning to read and write.

Experience tells us that the articulatory patterns of speech do not necessarily correlate with speech perception performance. This means that the claim that behind all articulatory deficiencies there must be some perceptual deficit as well is not true. However, some articulatory defects do cooccur with problems of perceptual functions. We have analysed whether, within the syndrome of developmental dysphasia, the speech perception processes of children with some speech defect significantly differ from those of children with no such defect. We tried to find out what degree of dissociation between production and perception could be found in the groups we examined. In view of the number of relevant subjects, the performance of six- and sevenyear-old subjects with some speech defect (see Table 5) was compared to that of those lacking such defects (the reason was that in the five-year-old group there were too many, whereas in the nine- and ten-year-old group there were too few children with some speech defect, hence comparison in these cases would not have made much sense).

Table 5

Correct speech perception by nursery pupils and schoolchildren with and without a speech defect

\begin{tabular}{|l|l|c|c|c|c|c|c|c|}
\hline \multirow{2}{*}{ TESTS } & \multicolumn{4}{|c|}{ SIX-YEAR-OLDS } & \multicolumn{4}{c|}{ SEVEN-YEAR-OLDS } \\
\cline { 2 - 9 } & \multicolumn{2}{|c|}{ No defect (\%) } & \multicolumn{2}{|c|}{ Defect (\%) } & \multicolumn{2}{c|}{ No defect (\%) } & \multicolumn{2}{|c|}{ Defect (\%) } \\
\cline { 2 - 9 } & Mean & Std. dev. & Mean & Std. dev. & Mean & Std. dev. & Mean & Std. dev. \\
\hline \hline GMP2 & 64.61 & 21.43 & 71.53 & 5.64 & 67 & 11.25 & 71 & 2.76 \\
GMP4 & 77.69 & 28.91 & 74.61 & 9.10 & 76 & 10.77 & 85 & 4.53 \\
GMP5 & 33.84 & 7.55 & 21.53 & 16.75 & 36 & 7.63 & 18 & 4.66 \\
GMP10 & 40 & 18.7 & 47.69 & 5.08 & 45 & 6.7 & 43 & 5.97 \\
\hline
\end{tabular}

With six-year-olds, children with a speech defect exhibited somewhat better performance than the others in two perceptual processes, but this difference 
is statistically not significant. Phonetic and phonological perception, on the other hand, was better with children who had no speech defect (although this difference was not significant, either). With seven-year-olds, the tendency was similar, the perception of children with a speech defect was again slightly better, even in terms of phonetic perception (but the differences were, again, not significant). In phonological perception, however, the performance of children with a speech defect was not only poorer but also significantly so $(p=0.014)$. These results suggest that phonetic and phonological perception are the components that crucially affect the articulatory movements, hence it can be assumed that such perception problems bear on production, too. However, we think that the better perception performance of children with a speech defect was also influenced by the fact that they had received speech therapy (production and perception therapy alike). This may explain the better perception results even in spite of actual speech defects.

The test of transformational perception was carried out with the schoolchildren only, given that a $100 \%$ score is only expected here from age seven onwards. In the first three parts of the test, we have not found significant differences in children's performances in any of the three groups. In the fourth part, however, the differences among the groups were significant $(\mathrm{p}=0.001)$; $73.37 \%$ of seven-year-olds, $53.3 \%$ of nine-year-olds, and $30 \%$ of ten-year-olds committed errors in solving the task (Figure 5).

$\longrightarrow-7$-year-olds $\square \quad$ 9-year-olds $-\square--10$-year-olds

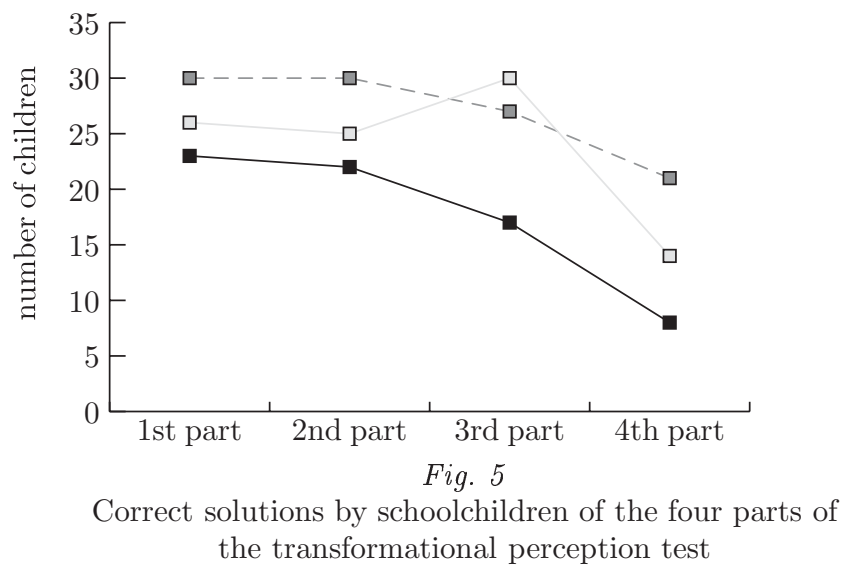

Although the children's performance improved with age, transformational perception that is indispensable for sound-letter identification did not work per- 
fectly in the case of most of our schoolchildren. The fact that their performance was perfect or nearly perfect on the first three subtests shows that the possibility of committing an error increases with the complexity of the task. According to our analyses, transformational perception exhibited strong correlation with performance on the serial perception task in all age groups $(\mathrm{r}=0.429)$.

Perception errors mainly showed quantitative differences across age groups; the types of errors, however, were identical or very similar. This unambiguously shows that the relevant perceptual processes were deficient in the same way. The actual errors committed were language specific and concerned various language areas of speech perception: speech sounds, sound sequences, certain parts of speech, suffixes, and erroneous activation of the mental lexicon. Some five/six-year-olds were characteristically unable to repeat the sentences they had heard in full; instead, they repeated more often just the end, less often just the beginning of those sentences. Typical errors committed by both nursery pupils and schoolchildren were the following: fewer syllables repeated (e.g., terítsék 'let them lay it' for terítsétek 'lay it! (pl.)' or barlangban 'in a cave' for barlangjukban 'in their cave'), incorrect suffixation (e.g., kergetik 'they chase it' for kergeti 'he chases it' or megyünk 'we go' for menjünk 'let us go' or tárgyalásba 'into a court hearing' for tárgyalásra 'to a court hearing'), omission of a sound (e.g., ejtsétek 'drop it! (pl.)' for fejtsétek 'solve it! (pl.)' or ártsatok 'do harm! (pl.)' for gyártsatok 'make! (pl.)'), and omission of a word ( $A$ strand be van zárva 'The swimming-pool is closed' for A strand ma be van zárva 'The swimming-pool is closed today'). Misperceived preverbs were also typical ( szállt fel 'got on' for szállt le 'got off'). Irrespective of their age, children did not hesitate to utter nonsense words in repetition tasks (e.g., gombó for gombod 'your button' or selejcsem for selejtet 'spoilage (acc.)' or balamba for A galamb $a .$. 'The pigeon the...'), sometimes the sequence they returned was only partially nonsensical (e.g., felesültek 'they x-ed up' for felesküdtek 'they took the oath'). Especially nursery pupils, but also seven-yearolds characteristically had seriality problems; e.g., Sokat esik tavasszal az esó for Tavasszal sokat esik az eső (both: 'It rains a lot in the spring') or Dobd a szemétkosárba a papirt for Dobd a papirt a szemétkosárba (both: 'Throw that piece of paper into the wastepaper-basket'). Where the task was the repetition of nonsense sequences, children's performance also showed typical errors due to perception problems - again, irrespective of age. The typical errors were: sound replacements of various types (seréb for zseréb, bakögy for bakôgy, jacolob for jacolov), omission of a sound (tankün for trankün), metathesis 
(sidiszami for siszidami), insertion of a sound (mendelékhej for menelékej), large-scale distortion of a sound sequence (piszposzposz for kriszposztyüvan).

\section{Conclusions}

The experimental results have confirmed our assumption that children who start speaking too late will, for quite a few years, remain delayed in their perception processes compared to what is expected at their age, even though their speech production will have greatly improved in the meantime. Therefore, a late-talker is to be regarded as having developmental dysphasia just as long as he shows a deficit, due to the delay, in any area of linguistic activity. Our data show that the perception processes of our subjects are delayed/impaired to a statistically relevant extent as compared to those of children who started talking in due time. In terms of phonological perception, those who also have a speech defect exhibit significantly poorer performance even among dysphasic children. The performance of the schoolchildren shows that there is no spontaneous improvement: dissociation can be detected even at the age of ten. In view of the fact that speech perception processes determine the quality of the acquisition of the written form of the mother tongue, the participants of our experiment predictably have/will have problems in learning how to read and write (Stackhouse-Wells 1997). A theoretical upshot of our results is that a close-knit but, in many respects, specifically variable interdependence between phonological representation and articulation program may be justified.

The lasting deficit of perceptual functions that we have found supports the performance-based theory as a causal explanation of developmental dysphasia. We cannot share the view that it is a specific language processing disorder since the fact that perception performance improves with age falsifies this. The assumed dissociation between mother-tongue speech production and speech perception doubtlessly obtains in the cases of developmental dysphasia that we have looked at. What is more, the nature of that dissociation undergoes a change between the ages of five and ten. It is of a lesser magnitude initially: two or three years after the child starts to speak, his delayed perception processes do not exhibit actual impairment (their functioning and relationships merely reflect an earlier stage of development). From school entry age, however, a significant change can be observed in that the dissociation increases and the functional delays turn into functional impairments. The question is whether this is an age-specific feature of developmental dysphasia as a syndrome or else it is a consequence of directed learning and/or the ac- 
quisition of the written language. In the first case, the qualitative change of dissociation occurs in all circumstances, whereas in the second, it is triggered by the beginning of schooling. The data seem to confirm the latter possibility. The developmental dysphasic child goes to school with a certain imbalance of production and perception but, in order to perform well at school, he would need the age-specific level of perceptual functions which he falls short of. However, the methods by which the various school skills are formed are suitable for normally developed children, not for dysphasic ones, therefore the development of the latters' perception processes becomes incidental and uncertain. This explains the fact that developmental dysphasia initially just means some delay in the development of the perception mechanism but later it becomes more serious and turns into an actual impairment. The facts emerging from our experimental data support the relative independence of speech production and speech perception, and suggest that their development may be a lot more divergent in case there is some defect than in the case of normal first language acquisition.

\section{References}

Aichison, Jean 1976. An introduction to psycholinguistics. Routledge, London \& New York.

Ball, Martin J. 1995. Phonetics for speech pathology. Whurr Publishers, London.

Berko Gleason, Jean - Nan Bernstein Ratner 1998. Language acquisition. In: Jean Berko Gleason - Nan Bernstein Ratner (eds.) Psycholinguistics, 347-409. Harcourt Brace College Publishers, Fort Worth.

Bishop, Dorothy V. 1992. The underlying nature of specific language impairment. In: Journal of Child Psychology and Psychiatry and Allied Disciplines 33: 3-66.

Chomsky, Noam 1957. Syntactic structures. Mouton, The Hague.

Coleman, John 1998. Cognitive reality and the phonological lexicon: a review. In: Journal of Neurolinguistics 1: 1-26.

Cromer, Richard F. 1991. Language and thought in normal and handicapped children. Academic Press, New York.

Crystal, David, Michael Garman - Paul Fletcher 1989. The grammatical analysis of language disability. Whurr Publishers, London.

Duvelleroy-Hommet, C., P. Gillet, C. Billard, M.L. Loisel, M.A. Barthez, J.J. SanitiniA. Autret 1995. Study of unilateral hemisphere performance in children with developmental dysphasia. In: Neuropsychologia 33: 823-34.

Evans, Julia L. 2001. An emergent account of language impairments in children with SLI: implications for assessment and intervention. In: Journal of Communication Disorders 34: $39-54$.

Gathercole, Susan - Alan Baddeley 1990. Phonological memory deficits in language disordered children: is there a casual connection? In: Journal of Memory and Language 29: 336-60. 
Gósy, Mária 1992. Speech perception. Forum Phoneticum 50. Hector, Frankfurt.

Gósy, Mária 1998. Speech perception and comprehension of dysphasic children. In: Wolfram Ziegler - Karin Deger (eds.) Clinical linguistics and phonetics, 29-36. Whurr Publishers, London.

Gósy, Mária 1999a. Evaluation of speech perception and comprehension processes of children: description and practical results. In: Maassen-Groenen (1999), 50-60.

Gósy, Mária 1999b. Synthesized speech for evaluation of children's hearing and acousticphonetic perception. In: Daryle Gardner-Bonneau (ed.) Human factors and voice interactive systems, 123-35. Kluwer Academic Publishers, Boston, Dordrecht and London.

Jakobson, Roman 1971. Toward a linguistic classification of aphasic impairments. Selected writings. Vol. 2: Words and language. Mouton, The Hague.

Kovac, Ilija, Berdij Garabedian, Christele Du Souich-Roberta M. Palmour 2001. Attention deficit/hyperactivity in SLI children increases risk of speech/language disorders in firstdegree relatives. A preliminary report. In: Journal of Communication Disorders 34: $339-54$.

Kraus, Nina, Therese J. McGee-Dawn Burton Koch 1999. Biology of speech sound perception and linguistic experience. In: Maassen - Groenen (1999), 117-37.

Ludlow, Christy L. 1980a. Children's language disorders: recent research advances. In: Annales Neurologica 7: 497-507.

Ludlow, Christy L. 1980b. Impaired language development: hypotheses for research. In: Bulletin of The Orton Society 30: 153-69.

Ludlow, Christy L., Edward A. Cudahy, Celia Bassich - Gerald L. Brown 1983. Auditory processing skills of hyperactive, language-impaired, and reading disabled boys. In: Elaine Z Lasky - Jack Katz (eds.) Central auditory processing disorders: Problems of speech, language and learning, 163-85. University Park Press, Washington.

Maassen, Ben - Paul Groenen (eds.) 1999. Pathologies of speech and language. Whurr Publishers, London.

MacWhinney, Brian 1998. Model of the emergence of language. In: Annual Review of Psychology 49: 199-227.

Menyhárt, Krisztina 2002. The temporal organisation of speech in monolingual and bilingual children. In: Acta Linguistica Hungarica 49: ??-??

Neijenhuis, Karin, Thom Crul, Ben Maassen - Paul Groenen 1999. Validation of a central auditory speech perception test for children. In: Maassen - Groenen (1999), 151-7.

Obler, Loraine K. - Kris Gjerlow 1999. Language and the brain. Cambridge University Press, Cambridge.

Palmour, Roberta 1997. Genetic studies of specific language impairment. In: Journal of Neurolinguistics 10: 215-30.

Paul, R.-M.E. Shiffer 1991. Communicative initiations in normal and late-talking toddlers. In: Applied Psycholinguistics 12: 419-33.

Psarommatis, Joannis M., Eleni Goritsa, Dimitrios Douniadakis, Michael Tsakanikos, Alexandra D. Kontrogianni - Nikolaos Apostolopoulos 2001. Hearing loss in speech-language delayed children. In: International Journal of Pediatric Otorhinolaryngology 58: 205-10.

Richardson, S.O. 1983. Differential diagnosis in delayed speech and language development. In: Folia Phoniatrica 35: 66-80.

Acta Linguistica Hungarica 49, 2002 
Rosen, Stuart, Heather van der Lely-Susan Dry 1997. Speech and nonspeech auditory abilities in two children with disordered language. In: Speech Hearing and Language 10: 1-17.

Stackhouse, Joy-Bill Wells 1997. Children's speech and literacy difficulties. A psycholinguistic framework. Whurr Publishers, London.

Steinberg, Danny 1993. An introduction to psycholinguistics. Longman, London.

Tallal, Paula 1980. Auditory temporal perception, phonics, and reading disabilities in children. In: Brain and Language 9: 182-98.

Tallal, Paula-M. Piercy 1975. Developmental aphasia: the perception of brief vowels and extended stop consonants. In: Neuropsychologia 13: 69-74.

Wieke, Marianne (ed.) 1977. Developmental dysphasia. Academic Press, London \& New York.

The literature has been partly surveyed by the help of the EISZ search bot of the Hungarian Ministry of Education.

Address of the author: Mária Gósy

Research Institute for Linguistics

Hungarian Academy of Sciences

Benczúr u. 33.

H-1068 Budapest

gosy@nytud.hu 